\title{
ECOLOGY OF Staphylococcus aureus AND ITS ANTIBIOTIC RE- SISTANCE GENES IN DAIRY FARMS: CONTRIBUTING FACTORS AND PUBLIC HEALTH IMPLICATIONS
}

\author{
Walid Elmonir ${ }^{1 \star}$, Hader Essa $^{1}$, Wael F. El-Tras ${ }^{2}$
}

\begin{abstract}
${ }^{1}$ Hygiene and Preventive Medicine (Zoonoses) Department, Faculty of Veterinary Medicine, Kafrelsheikh University, Kafrelsheikh 33516, Egypt, ${ }^{2}$ Faculty of Aquatic and Fisheries Sciences (Zoonoses), Kafrelsheikh University, Egypt
\end{abstract}

*Corresponding author, E-mail: walid.elmonir@gmail.com

\begin{abstract}
Dairy farms are major sources for zoonotic Staphylococcus aureus pathogens and their antibiotic resistance genes. This study was conducted to assess critical sources and factors related to dissemination of $S$. aureus and its resistance genes within dairy farms in Egypt. In addition, workers' knowledge, attitudes and practices (KAPs) was evaluated. A total of 102 pooled samples were collected from 3 medium-scale dairy farms in Egypt. S. aureus was detected in $72.5 \%$ of the examined samples: lactating cows (72.9\%), workers (81.5\%), barns environment (88.9\%), milking equipment (40\%), and bulk tank milk (100\%). Cows (udder milk and nostril), workers (hand skin and nostril), barns, open-sides parlor, and lack of acid rinse were associated with $S$. aureus contamination of milking equipment $(P=0.004-0.04)$. Methicillin resistant $S$. aureus (MRSA, mecA+), vancomycin-resistant $S$. aureus (VRSA, vanA+) and methicillin-vancomycin-resistant S. aureus (MVRSA, mecA+-vanA+) represented $27.5 \%, 5 \%$ and $12.5 \%$ of S. aureus isolates, respectively. This is the first report of MVRSA in dairy farms in Egypt. For workers KAPs, $48.7 \%$ didn't know milk-borne zoonoses, while their high risk practices included consumption of raw milk (52.2\%), lack of hand wash (48.7\%), and willing to work with sore throat $(82.6 \%)$. This study highlights the critical sources of $S$. aureus pathogens and their antibiotic resistance genes in dairy farms. This will help in reforming biosecurity plans in dairy farms; an urgent demand for consumers safety in Egypt.
\end{abstract}

Key words: Staphylococcus aureus ecology; dairy farms; antibiotic resistance genes; public health implications

\section{Introduction}

Staphylococcus aureus is the third most recorded etiology of food-borne diseases worldwide (1), and it is one of the top causes of mastitis in dairy animals (2). Dairy farms are major reservoirs of $S$. aureus pathogens. The pathogen can circulate within the farm through cow, workers, farm environment and may occasionally pass to bulk tank milk posing a public health risk for consumers $(1,3)$. Another major public health concern is the continuous evolving of antibiotic resistant strains of $S$. aureus. Methicillin resistant $S$. aureus (MRSA) is a global public health hazard. Reports of dairy farms associated MRSA are rising worldwide 
$(1,4,5)$. Misuse and overuse of antimicrobials in dairy farms for therapy (e.g. clinical mastitis) or prevention (e.g. dry cow) may evolve resistance mechanisms in $S$. aureus and fasten the emergence of multi-drug resistant strains as MRSA. The ecology of MRSA in dairy farms is complex and the exchange of strains in-between cows, workers and farm environment was recorded (5). This continuous inter-sources transaction helps in persistence of MRSA infection in the farm, which may pose an animal health risk for dairy animals and a zoonotic risk for workers. Occupation exposure to MRSA may be increased by inadequate awareness and unhygienic practices as raw milk consumption, inadequate use of personal protective equipment (PPE) or hand washing (6). Dairy farm associated MRSA threat may extend to public health if these strain gain access to bulk milk or spread environmentally through contaminated air, water, or manure to population in close proximity to dairy farms (2).

In last few years, a new resistance genotype assigned as vancomycin resistant $S$. aureus (VRSA) has emerged when a MRSA isolate gained vanA gene and expressed resistance to vancomycin in a clinical case (7).Humans' clinical reports of VRSA infection are expanding in the Middle East, particularly in Egypt (8). However, dairy farm associated VRSA was never recorded in Egypt and also very limited data are available worldwide (9).

Identifying critical sources of $S$. aureus propagation in dairy farms will guide implementation of preventive strategies to improve both animal health and consumers' safety. Therefore, the objectives of the study were to evaluate the role of lactating cows, workers and barns environment as potential critical sources of $S$. aureus pathogens in dairy farms, to assess the factors contributing to their dissemination to milking equipment, and to determine the frequency and diversity of their antibiotic resistance genotypes. Knowledge, attitudes and practices (KAPs) of dairy workers were also recorded.

\section{Materials and methods}

\section{Dairy farms}

The study was conducted in 3 medium-scale dairy farms (A, B and C) located in Kafrelzayat district (3049'14" N and 3048'57" E), Gharbia Governorate, Egypt. Numbers of lactating cows were 63, 90 and 122 for A, B and C farms, respectively. Lactating cow barns in the three farms were open yards with cow sheds and soil bedding. Parlors in the three farms were pipeline milking machines. In farms $\mathrm{A}$ and $\mathrm{B}$, the parlors were open-sides with only half length walls surrounding the parlor, while in farm $\mathrm{C}$ the parlor was closed with windows and gates. Teat dipping was conducted in farms B and C. Cleaning of milking equipment was conducted by hot alkaline detergent wash in farms $\mathrm{A}$ and $\mathrm{B}$, while two-step sequential alkaline detergent wash followed by acid rinse was conducted in farm C. In farm A, milk was sold raw to consumers, while in farms B and $C$ the milk was sold to processing plants.

\section{Samples collection}

A total 102 pooled samples were collected from cows, workers, barns, milking equipment and bulk tank milk in the 3 farms during the period between October 2016 and February 2017.

Cows, workers and barn environment: all samples were collected according to Roberson et al. (10). For cows, 16 pooled samples were collected in each farm: 5 samples of composite udder milk (25 cows) and 5 samples of nasal swabs (25 cows), 3 samples (15 cows) of udder skin and 3 samples (15 cows) feces samples. For workers, 9 pooled samples were collected per farm: 3 samples (15 workers) for each of hands skin swabs, nasal swabs and stool samples. For barns environment: 3 pooled samples were collected per farm: 1 sample (500-1000 g or $\mathrm{ml}$ ) for each of bedding, feed and water.

Milking equipment and BTM: samples were collected according to Lee et al. (3). Five pooled samples (20 teat cups) of milking equipment and one pooled sample $(500 \mathrm{ml})$ of BTM were collected per each farm. All samples were transported in ice-box to the laboratory within 2 hours to be processed. 
Detection and molecular analysis of S. aureus

All samples were cultured on Baired Parker Agar (Oxoid, Hampshire, U.K.) supplemented with Egg Yolk Tellurite (50mL/L) (Oxoid, Hampshire, U.K.) and incubated at $37^{\circ} \mathrm{C}$ for $24-$ 48 hours. Identification based on biochemical and tube coagulase tests was conducted as previously described (11).

DNA extraction from overnight broth cultures was conducted using QIAamp DNA Mini kit (Qiagen, Hilden, Germany) according to the manufacturer's instructions. Detection of mecA and vanA genes as molecular determinants of MRSA and VRSA, respectively was conducted using multiplex PCR according to Amghalia et al. (12). The primers mecA (F): 5'AAAATCGATGGTAAAGGTTGGC'3 and mecA (R): 5'AGTTCTGCAGTACCGGATTTGC'3 were used to amplify 533 bp of mecA gene. The primers vanA (F): 5'CATGAATAGAATAAAAGTTGCAATA'3 and vanA (R): 5'CCCCTTTAACGCTAATACGATCAA'3 were used to amplify 1030 bp of vanA gene. The reaction mixture contained $12.5 \mu \mathrm{l}$ EmeraldAmp Max PCR Master mix (Takara Bio, Kusatsu, Japan), $1 \mu \mathrm{l}$ (10 pmol) of each primer, $3 \mu$ l of DNA template ( $50 \mathrm{ng}$ ) and water up to $25 \mu 1$ reaction volume. Cycling conditions started with an initial denaturation step at $94^{\circ} \mathrm{C}$ for $5 \mathrm{~min}, 10$ cycles of amplification $\left(94^{\circ} \mathrm{C}\right.$ for $30 \mathrm{sec} ; 64^{\circ} \mathrm{C}$ for $30 \mathrm{sec} ; 72^{\circ} \mathrm{C}$ for $45 \mathrm{sec}$ ), then followed by another 25 cycles of amplification $\left(94^{\circ} \mathrm{C}\right.$ for $45 \mathrm{sec} ; 50^{\circ} \mathrm{C}$ for $45 \mathrm{sec} ; 72^{\circ} \mathrm{C}$ for 1 min), and ending with a final extension at $72^{\circ} \mathrm{C}$ for $10 \mathrm{~min}$. PCR products were electrophoresed in $2 \%$ agarose gel with ethidium bromide and photographed under UV illumination (Fig. 1).

Knowledge, attitudes and practices (KAPs) questionnaire

KAPs of farm workers (23 workers) were assessed using a pre-tested semi-structured questionnaire. The questionnaire recorded knowledge of milk-borne zoonoses and practices regarding milk consumption, personal hygiene (hand washing), using PPE, and working with illness (sore throat or diarrhea).

\section{Statistical analysis}

Factors association with milking equipment contamination with $S$. aureus was estimated using Fisher's Exact test and Pearson's R correlation coefficient on SPSS v19 (SPSS Inc. 2010). Significant association was recorded at $P<0.05$.

\section{Ethical approval}

All research details were explained to dairy farm owners and workers. Their written consents were obtained.

\section{Results and discussion}

High rate of S. aureus dissemination in diverse sources within dairy farms will eventually reside in bulk tank milk and consequently passes to consumers as public health hazards.

Prevalence of S. aureus in Farm level and in bulk tank milk (BTM)

The prevalence of S. aureus at farm level ranged from 67.6 to $76.5 \%$ with overall prevalence of $72.5 \%$ (Table 1 ). These rates were higher than other reports from dairy farms in Brazil (6.6\%) and Ethiopia (19.6\%) by Lee et al. (3) and Ayele et al. (6), respectively. Examined BTM samples from all farms harbored S. aureus (100\%). Lower rate $(21.7 \%)$ were reported in Brazil (3), however our finding lined with that of Haran et al. (1) who detected S. aureus in BTM samples from $84 \%$ of the examined dairy farms in USA.

Critical points for S. aureus dissemination in dairy farms

Dairy cows, workers, barns environment, and milking equipment are critical points for dissemination of S. aureus within dairy farms.

\section{Dairy cows}

Cows are primary reservoirs of S. aureus in dairy farms. The overall prevalence of S. aureus in Cows' samples was $72.9 \%$ (Table 1). This high rate was in line with findings of Jørgensen et al. (13), who reported S. aureus in $90.1 \%$ of examined cows in a small-scale dairy farm in Norway. S. aureus was detected in udder milk (86.7\%), nostrils (80\%), feces 
(55.6\%), and udder skin (55.6\%) samples (Table 1). Prevalence of S. aureus in udder milk in this study was higher than other reports (5.5 $36.4 \%$ ) from Norway (13), Brazil (3), and Ethiopia (6). Nostrils carriage rate was higher than another report (3.2\%) in Turkey (14). Fecal prevalence rate in this study was higher than previous reports (1.6 - 12\%) in Greece (15) and USA (10). Udder skin rate was higher than that reported (8.4\%) in USA (10) but lower than that reported (90.1\%) in Norway (13). There was no association between cows' samples (udder milk, nostrils, feces or udder skin). In contrast, Piccinini et al. (16) suggested a persistent association between udder skin and intra-mammary infection in dairy cows. However, our finding agreed with Zadoks et al. (17), who reported minor role of teat skin infection in intra-mammary carriage of $S$. aureus.

Table 1: Frequency distribution of S. aureus pathogens and their association with milking equipment contamination in examined dairy farms

\begin{tabular}{|l|l|l|l|l|l|l|}
\hline \multicolumn{2}{|l|}{ Variables } & Farm A & Farm B & Farm C & Total & $P$-value \\
\hline \multirow{4}{*}{ Cows } & Udder Milk & 100 & 80 & 80 & 86.7 & 0.01 \\
\cline { 2 - 7 } & Nostril & 80 & 60 & 100 & 80 & 0.03 \\
\cline { 2 - 7 } & Udder skin & 66.7 & 0 & 100 & 55.6 & 0.4 \\
\cline { 2 - 7 } & Feces & 33.3 & 66.7 & 66.7 & 55.6 & 0.4 \\
\cline { 2 - 7 } & Subtotal & 75 & 56.3 & 87.5 & 72.9 & 0.02 \\
\hline \multirow{4}{*}{ Workers } & Nostril & 66.7 & 100 & 100 & 88.9 & 0.02 \\
\cline { 2 - 7 } & Hand skin & 100 & 100 & 100 & 100 & 0.004 \\
\cline { 2 - 7 } & Stool & 0 & 66.7 & 100 & 55.6 & 0.4 \\
\cline { 2 - 7 } & Subtotal & 55.6 & 88.9 & 100 & 81.5 & 0.01 \\
\hline Barns & 100 & 100 & 66.7 & 88.9 & 0.02 \\
\hline Milking equipment & 40 & 80 & 0 & 40 & - \\
\hline Bulk milk & 100 & 100 & 100 & 100 & - \\
\hline Total & 67.6 & 73.5 & 76.5 & 72.5 & - \\
\hline
\end{tabular}

*All frequency results are represented as percent

Table 2: Parlor design and practices associated with milking equipment contamination with S. aureus in this study

\begin{tabular}{|c|c|c|c|c|c|c|c|}
\hline \multirow{2}{*}{ Variable } & \multirow{2}{*}{ Categories } & \multicolumn{3}{|c|}{ Farms } & \multirow{2}{*}{ Percent } & \multicolumn{2}{|c|}{$P$-value } \\
\hline & & A & B & $\mathrm{C}$ & & F & $\mathrm{R}$ \\
\hline \multirow{2}{*}{$\begin{array}{l}\text { Parlor de- } \\
\text { sign }\end{array}$} & Open-sides & 1 & 1 & 0 & 66.7 & \multirow{2}{*}{0.04} & +0.02 \\
\hline & Close-sides & 0 & 0 & 1 & 33.3 & & -0.02 \\
\hline \multirow{6}{*}{$\begin{array}{l}\text { Parlors } \\
\text { practices }\end{array}$} & Teat dip & 0 & 1 & 1 & 66.7 & \multirow{2}{*}{0.7} & 1 \\
\hline & No Teat dip & 1 & 0 & 0 & 33.3 & & 1 \\
\hline & $>$ Once/day cleaning 1 & 0 & 1 & 1 & 66.7 & \multirow{2}{*}{0.7} & 1 \\
\hline & Once/day cleaning & 1 & 0 & 0 & 33.3 & & 1 \\
\hline & Acid rinse & 0 & 0 & 1 & 33.3 & \multirow{2}{*}{0.04} & -0.02 \\
\hline & No acid rinse & 1 & 1 & 0 & 66.7 & & +0.02 \\
\hline
\end{tabular}

1: cleaning of milking equipment after milking cycle. F: Fisher's Exact test R: Pearson's R correlation coefficient 


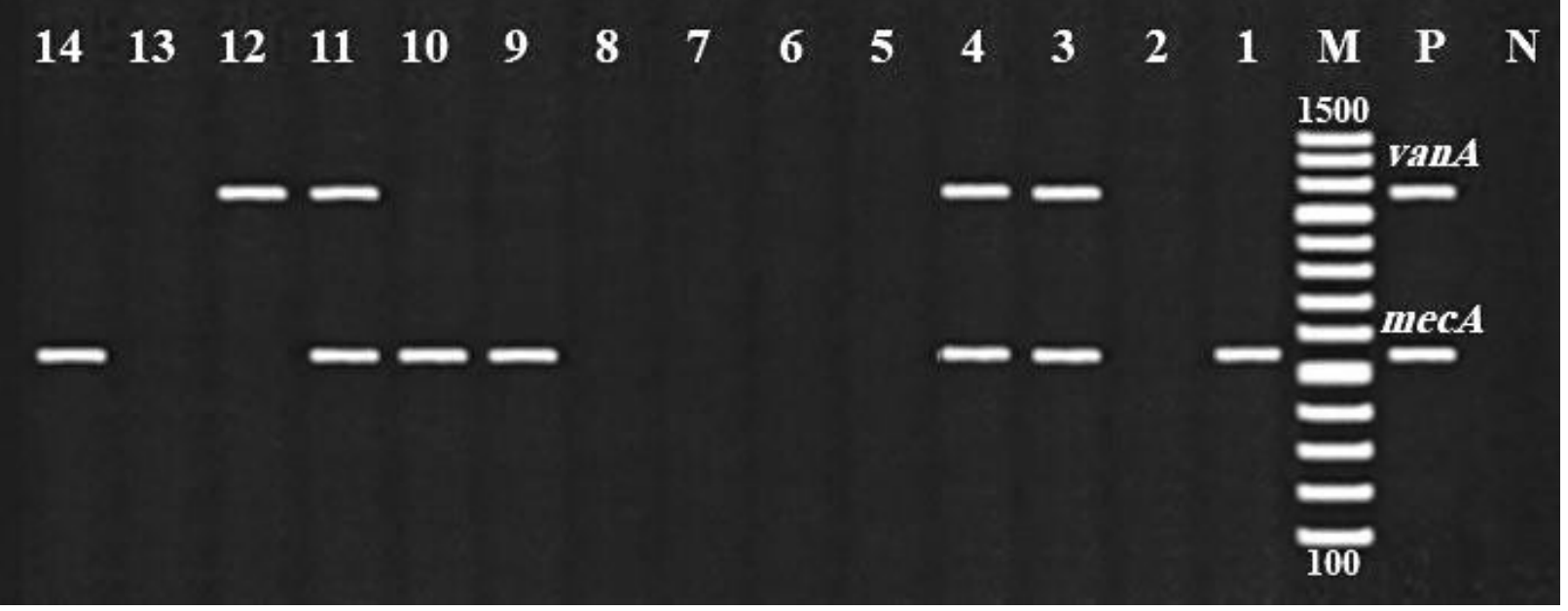

Figure 1: Molecular detection of antibiotic resistance genes (mecA and vanA) among S. aureus pathogens isolated from different samples in farm A. mecA gene: 533 bp, vanA gene: $1030 \mathrm{bp}$, Lanes 1-6: Cows' isolates, Lane 7: Milking equipment's isolates, Lanes 8-10: Barns' isolates, Lanes 11-14: Workers' isolates, M: 100 bp DNA marker, P: Positive control, and N: Negative control

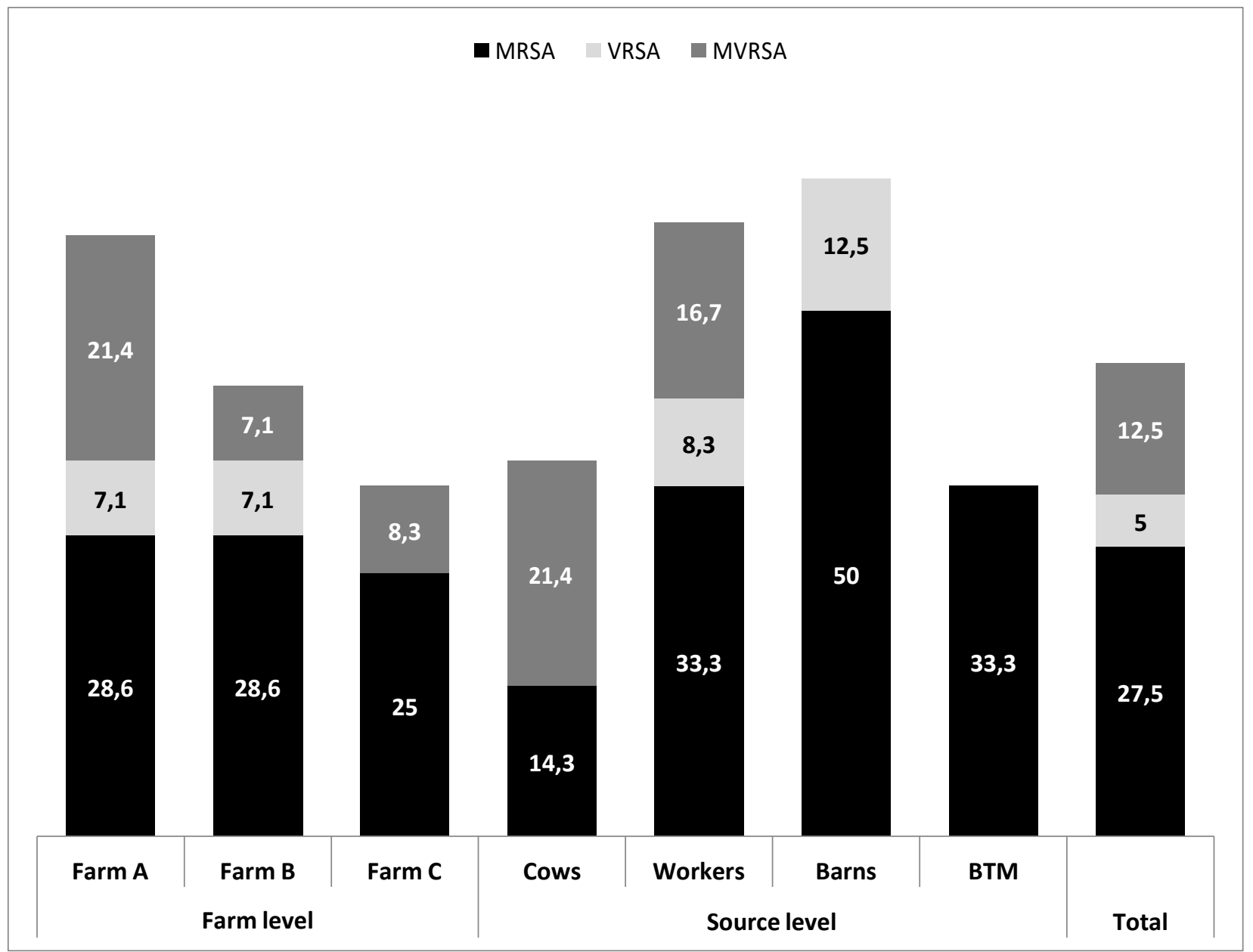

Figure 2: Frequency distribution of antibiotic resistance genotypes among $S$. aureus pathogens isolated from examined farms. MRSA: Methicillin resistant $S$. aureus (mecA+), VRSA: Vancomycin-resistant $S$. aureus (vanA+) and MVRSA: Methicillin-vancomycin-resistant S. aureus (mecA+ -vanA+). BTM: Bulk tank milk. All frequency results are represented as percent 


\section{Farm workers}

Farm worker are at risk of occupational infection with livestock associated $S$. aureus infection. In addition, they may play a critical role in dissemination of infection to cows, equipments, farm environment, and milk $(3,10,17)$. The overall prevalence of S. aureus in workers' samples was $81.5 \%$, which was higher than a report (27\%) in USA (10). S. aureus was detected in nostrils (88.9\%), hand skin (100\%), and stool (55.6\%) samples from workers in this study (Table 1). Nostrils prevalence was higher than a report (29.3\%) in Turkey (14). Lower rates for hand skin (3.3 - 32\%) were reported in Brazil (3) and Ethiopia (6). Intestinal colonization and stool carriage of $S$. aureus in humans were previously reported (18). There was a significant association $(\mathrm{P}=0.04)$ between hand skin and fecal carriage of $S$. aureus. Same association was recorded in USA (18). This could be attributed to lack of adequate personnel hygiene of examined workers as improper hand washing. No other association was recorded between workers samples.

\section{Barns environment}

Barns environment may act as a vehicle for S. aureus transmission to cows, workers, farm equipment and BTM $(10,13)$. S. aureus was detected in $88.9 \%$ of the examined barn samples (Table 1), which was higher than other reports (1-20\%) in USA (10) and Norway (13).

\section{Milking equipment}

Milking equipment are critical vehicles for dissemination of $\mathrm{S}$. aureus between individual dairy cows as well as from barns, cows and worker to milk $(3,17)$. In the present study, S. aureus was isolated from $40 \%$ of milking equipment (Table 1). This was higher than other reports (2.1-11.1\%) in USA (10), Brazil (3) and Ethiopia (6).

High rates of $S$. aureus detection in various sources in examined dairy farms highlight their role as critical points for $\mathrm{S}$. aureus dissemination and may also refer to unsanitary dairy farm practices. This is an alarming threat for both dairy animals and public health. Differences in the prevalence rates may be due to variations in the farm sanitary conditions, animal breeds, animal health status (e.g. subclinical mastitis), sampling strategies, seasons and geographical locations.

Factors contributing to milking equipment contamination with S. aureus in dairy farms

Carriage of S. aureus via cows, workers and barns was significantly associated with milking equipment contamination $(\mathrm{P}=0.01$ - 0.02) (Table 2). Nostrils (cows and workers), udder milk (cows) and hand skin (workers) were the sources that contributed significantly to milking equipment contamination $(\mathrm{P}=0.004-0.03)$ (Table 2). Our finding agreed with Zadoks et al. (17) who confirmed S. aureus transmission from hand skin and udder milk to the milking equipment.

Open-sides parlors design positively associated with milking equipment contamination $(\mathrm{P}=$ 0.04) (Table 2). This could be linked to the significant effect of contaminated barns environment. With open-sides parlors walls, air drafts can introduce infection from contaminated barns to parlors during and in between milking cycles.

Lacking of acid rinse was significantly associated with milking equipment contamination $(\mathrm{P}=0.04)$ (Table 2). This finding agreed with Elmoslemany et al. (19) who reported the positive association between inadequate acid rinse and milk contamination within dairy farms. Acid rinse removes milk stones, which could act as niches for microbial growth within milking equipment (19). Also acid has antibacterial activity against broad range of bacteria (20). Both mechanisms may explain the significant effect of acid rinse in reducing $S$. aureus contamination of milking equipment.

Teat dip was not associated with milking equipment contamination in this study (Table 1). However it may be contributed to the elimination of teat skin role in contaminating milking equipment as recorded in this study $(\mathrm{P}=0$. 4) (Table 1). 
Frequency distribution of S. aureus antibiotic resistance genotypes in dairy farms

Almost half (45\%) of the S. aureus isolates carried at least 1 antibiotic resistance gene. MRSA (mecA+), VRSA (vanA+), and MVRSA (mecA+, vanA+) resistance genotypes represented $27.5 \%, 5 \%$, and $12.5 \%$ of $S$. aureus isolates respectively (Fig. 2). MRSA isolates were detected in cows, workers, barns, and BTM. VRSA isolates were from workers and barns, while MVRSA isolates were from cows and workers. Hence, workers were the only source that harbored the 3 resistance genotypes in the examined farms. In agreement with our findings, MRSA isolates were detected in cows, workers, and environment of dairy farms in Korea (4) and Italy (5). VRSA isolates were reported in cows with mastitis in China (9). However, as far as we know, this the first report of MVRSA in dairy farms in Egypt. Detection of MVRSA isolates in dairy farms is alarming and their emergence requires further investigation. MRSA acquiring vanA gene by plasmid transfer was previously reported in human clinical cases (21). Same mechanism of gene transfer could explain the emergence of MVRSA in this study. High rate of intersources transmission and mixing of $S$. aureus isolates within same farm may facilitate this gene transfer. The detection of the 3 genotypes in 2 farms (A and B) and the findings of Locatelli et al. (5), who reported MRSA genotypes exchange between cows, workers and environment within same dairy farm, support our hypothesis. Yet, further investigation is required to elucidate the ecology and molecular bases of MVRSA emergence in dairy farms.

Knowledge, attitudes and practices of farm workers

Among respondents, 47.8\% lacked awareness regarding milk-borne zoonoses, which was lower than that (87\%) reported in Ethiopia (6). Raw milk consumption was reported by $52.2 \%$ of the workers. This was higher than another report (35\%) of raw milk consumption by dairy workers in Ethiopia (6). None of workers used PPE (gloves or masks) during work. Around half (47.8\%) of workers don't wash their hands, which was lower than that reported in Ethiopia where none of the workers (100\%) wash their hands (6). Finally, $82.6 \%$ and $73.9 \%$ of the worker would work with sore throat and diarrhea, respectively. Lack of awareness and unhygienic practices (raw milk consumption, lack of hand wash and PPE use) may pose an occupational zoonotic threat for the workers in these farms. In addition the unhygienic practices and willing to work with illness may contribute to the significant role of workers in disseminating S. aureus contamination in examined farms.

\section{Conclusion}

This study records high dissemination rate of S. aureuspathogens and their antibiotic resistance genes in dairy farms in Egypt, which may impact the health of dairy products consumers in Egypt. The study also highlights the critical points and practices associated with $\mathrm{S}$. aureus dissemination in dairy farms, which will help in improving biosecurity planning and application in dairy farms in Egypt.

\section{References}

1. Haran KP, Godden SM, Boxrud D, Jawahir S, Bender JB, \&Sreevatsan S. Prevalence and Characterization of Staphylococcus aureus, Including Methicillin-Resistant Staphylococcus aureus isolated from Bulk Tank Milk from Minnesota Dairy Farms. Journal of Clinical Microbiology 2012; 50: 688-95.

2. Smith TC. Livestock-Associated Staphylococcus aureus: The United States Experience. PLoS Pathogens 2015; 11: e1004564.

3. Lee SH, Camargo CH, Gonçalves JL, Cruz AG, Sartori BT, Machado MB \& Oliveira CA. Characterization of Staphylococcus aureus isolates in milk and the milking environment from smallscale dairy farms of São Paulo, Brazil, using pulsedfield gel electrophoresis. Journal of Dairy Science 2012; 95: 7377-83.

4. Lim SK, Nam HM, Jang GC, Lee HS, Jung SC \& Kim TS. Transmission and persistence of methicillin-resistant Staphylococcus aureus in milk, environment, and workers in dairy cattle farms. Foodborne Pathogens and Diseases 2013;10:731-6.

5. Locatelli C, Cremonesi P, Caprioli A, Carfora V, Ianzano A, Barberio A, Morandi S, Casula A, Castiglioni B, Bronzo V \&Moroni P. Occurrence of methicillin-resistant Staphylococcus aureus in dairy 
cattle herds, related swine farms, and humans in contact with herds. Journal of Dairy Science 2017; 100: 608-19.

6. Ayele Y, Gutema FD, Edao BM, Girma R, Tufa TB, Beyene TJ, Tadesse F, Geloye M \&Beyi AF. Assessment of Staphylococcus aureus along milk value chain and its public health importance in Sebeta, central Oromia, Ethiopia. BMC Microbiology 2017; 17: 141.

7. Centers for Disease Control and Prevention (CDC). Staphylococcus aureus resistant to vancomycin--United States, 2002. Morbidity and Mortality Weekly Report (MMWR) 2002; 51: 565-7

8. Rahimipour F, Ghazvini K\&Youssefi M. Reports of Vancomycin-Resistant Staphylococcus aureus from Middle East Countries, Archives of Clinical Infectious Diseases 2018;13: e59522.

9. Feng Y, Qi W, Xu-rong W, Ling W, Xin-pu L, Jin-yin L, Shi-dong Z, Hong-sheng L. Genetic characterization of antimicrobial resis-tance in Staphylococcus aureus isolated from bovine mastitis cases in Northwest China. Journal of Integrative Agriculture 2016; 15:2842-7.

10. Roberson JR, Fox LK, Hancock DD, Gay JM \&Besser TE. Ecology of Staphylococcus aureus isolated from various sites on dairy farms. Journal of Dairy Science 1994; 77: 3354-64.

11. Elmonir W, Abo-Remela EM \&Sobeih A. Public health risks of Escherichia coli and Staphylococcus aureus in raw bovine milk sold in informal markets in Egypt. Journal of Infection in Developing Countries 2018; 12: 533-41.

12. Amghalia E, AL-Haj N, Shamsudin M, Radu S, Rosli R, Neela V \& Rahim R. Multiplex PCR assays for the detection of clinically relevant antibiotic resistance genes in Staphylococcus aureus isolated from Malaysian hospitals. Research Journal of Biological Sciences2009; 4: 444-8.

13. Jørgensen HJ, Mørk T \&Rørvik LM. The occurrence of Staphylococcus aureus on a farm with small-scale production of raw milk cheese. Journal of Dairy Science2005; 88: 3810-7.

14. Garipcin M \&Seker E. Nasal carriage of methicillin-resistant Staphylococcus aureus in cattle and farm workers in Turkey. VeterinarskiArhiv 2015; 85: 117-29.

15. Dimitracopoulos G, Kalkani-Boussiakou H \&Papavassiliou J. Animal fecal carriership and biotypes of Staphylococcus aureus. Applied and Environmental Microbiology 1977; 34: 461-4.

16. Piccinini R, Cesaris L, Daprà V, Borromeo V, Picozzi C, Secchi C \&Zecconi A. The role of teat skin contamination in the epidemiology of Staphylococcus aureus intramammary infections. Journal of Dairy Science 2009; 76: 36-41.

17. Zadoks RN, van Leeuwen WB, Kreft D, Fox LK, Barkema HW, Schukken YH \& van BelkumA.Comparison of Staphylococcus aureus isolates from bovine andhuman skin, milking equipment, and bovine milk by phage typing,pulsed-field gel electrophoresis, and binary typing. Journal of Clinical Microbiology 2002; 40:3894-902.

18. Bhalla A, Aron DC \&Donskey CJ. Staphylococcus aureus intestinal colonization is associated with increased frequency of S. aureus on skin of hospitalized patients. BMC Infectious Diseases 2007; 7: 105.

19. Elmoslemany AM, Keefe GP, Dohoo IR, Wichtel JJ, Stryhn H \&Dingwell RT. The association between bulk tank milk analysis for raw milk quality and on-farm management practices. Preventive Veterinary Medicine 2010; 95: 32-40.

20. Reinemann DJ, Wolters GMVH, Billon P, Lind O, Rasmussen MD. Review of practices for cleaning and sanitation of milking machines. 2000. Available athttps://milkquality.wisc.edu/wp-content/uploads/sites/212/ 2011/10/review-of-practices-for-cleaning.pdf (Accessed 10 November 2018).

21. Rossi F, Diaz L, Wollam A, Panesso D, Zhou Y, Rincon S, Narechania A, Xing G, Di Gioia TS, Doi A, Tran TT, Reyes J, Munita JM, Carvajal LP, Hernandez-Roldan A, Brandão D, van der Heijden IM, Murray BE, Planet PJ, Weinstock GM \& Arias CA. Transferable vancomycin resistance in a community-associated MRSA lineage. New England Journal of Medicine 2014; 370: 1524-31. 